\title{
The Effect of Unbalance on the Cyclic Stresses of a Flexible Rotor Mounted on Oil-Film Bearings Using Finite Elements Technique
} (ANSYS)

\author{
Kh. E. Hammo \\ A. M. Abdullah \\ O. A. Mohammed \\ (Ass. Lecturer) \\ Mechanical Engineering Department / College of Engineering / University of Mosul
}

\begin{abstract}
Eccentricity problem is considered as one of the most important and common repeated problems in rotary shafts in all machines. This will lead to generation of vibration and extra loads on bearings. Also a non-uniformity can occur in distribution of applied load on all the surface of the bearing which being concentrated on one or two sides of the bearing surface. The purpose of this research is to investigate the effect of the unbalance on the values of stresses and deflections for a flexible rotor supported by oil film bearings. Various rotational speeds and unbalance effects has been taken in to consideration. A dynamical model of the system has been built. The parameters of journal bearing have been determined using MATLAB/ simulink software. ANSYS program has been used for the analysis of the stresses produced during rotation.

Keywords: Unbalance, Eccentricity, Simulation, Rotor Shaft.

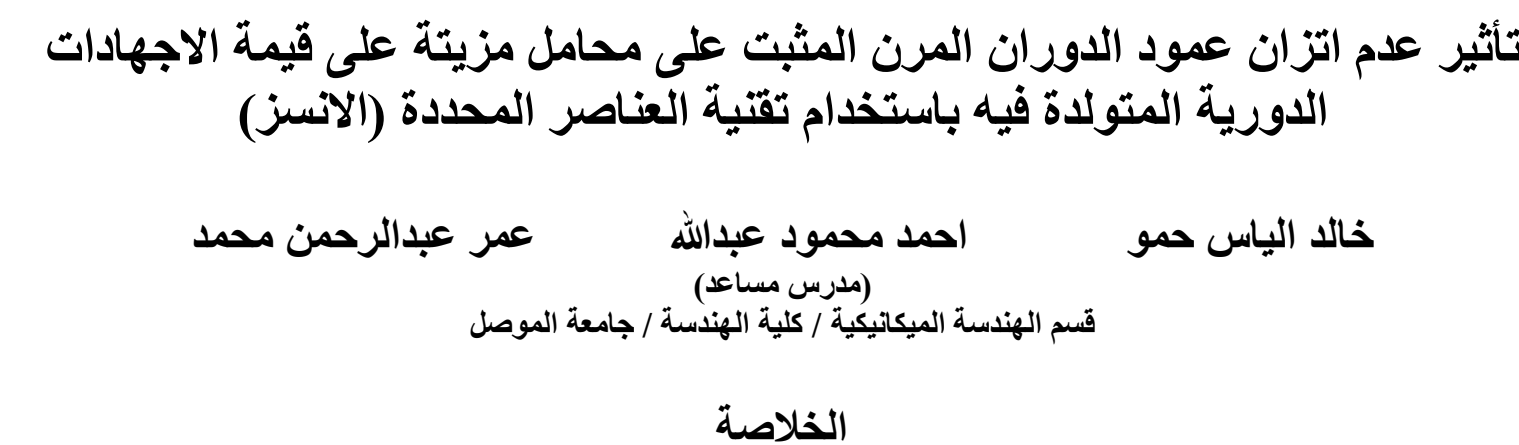

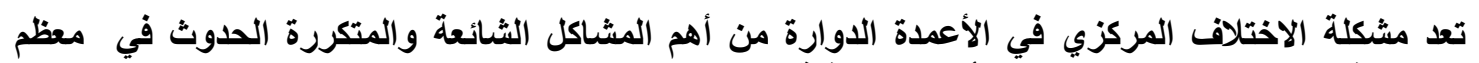

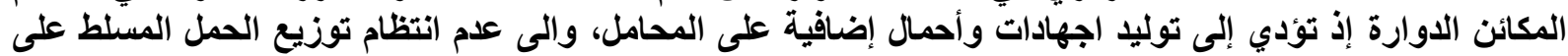

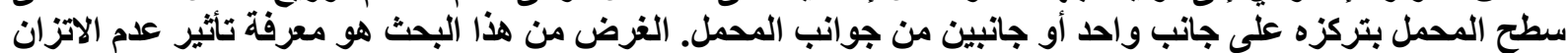

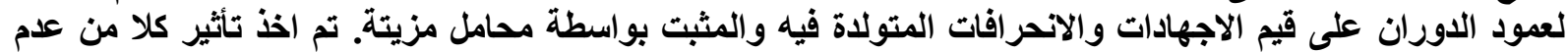

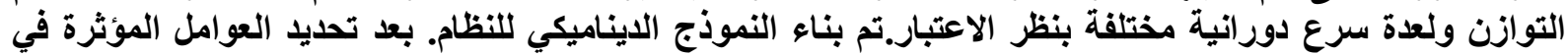

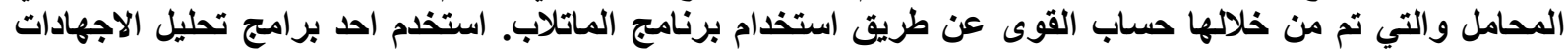

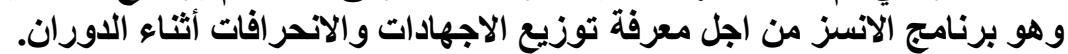

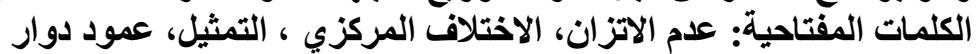




\section{Introduction}

Rotating machinery is extensively used in diverse engineering applications. The accurate prediction of dynamic characteristics, such as, critical speeds, natural whirl frequencies, instability thresholds and response to mass unbalance, is important in the design of any type of rotating machinery.

As the modern world progresses, the demand on products has asked more about their functionality than their appearance. The finite element method (FEM) is a powerful tool and has been applied to numerous analyses. One advantage of FEM is that it could save time and cost for engineers in the development of new products. In the beginning of the research and development of a product, the finite element model of the product is constructed and static and dynamic analyses are conducted on the model to obtain the simulation results as the first engineering assessments. Experiences have indicated that the selected parameters of the numerical model such as element type, material model, contact conditions, etc. might introduce errors to the simulated results. Thus, the numerical model needs to be verified by experimental means; for example, a numerical modal analysis should be further verified by the results of a modal testing [1].

In the general area of rotor dynamic analysis, several researchers have studied the use of the finite element method for modeling rotor systems. Elmadany, M. et al [2] have included in their finite element modeling of the rotor, the effects of rotary inertia, gyroscopic moments, internal viscous and hysteretic damping, shear deformations, and axial torque. A more comprehensive study of the subject was later presented by Khonsari and Kim[3] which confirmed the non-linear nature of the clearance loss as a function of time. Hariharan V. et al [4] are focused in their study on the experimental and numerical (ANSYS) frequency spectra to obtain the rotor shaft acceleration using dual channel vibration analyzer under the misalignment condition. Similarities between the dynamic response of beams and rotor-shaft systems have enabled many approaches, to critical speed identification, to be based on the transverse beam, vibration problem, $[5,6]$. These include the energy methods, the influence coefficient technique, Dunkerley's formulation, etc., all of which ignore the effect of rotational speed and hence the rotor dynamic, gyroscopic couple. Al-Khazali, H. A. et al [7] investigated the effects of modal parameters on the noise produced by rotor-bearing systems under gyroscopic effect. They studied reaction forces in bearings with high speed of rotation using ANSYS 12. Pasha, H. G. [8] utilized the finite element program for modeling and analyzing flexible rotor-bearing system supported on linear stiffness and viscous damping bearings using effects of rotary inertia, gyroscopic moments and axial load. Nikolakopoulos et al. [9] presented an analytical model in order to find the relationship among the friction force, the misalignment angles and wear depth. The Reynolds equation is solved numerically and the friction force is calculated in the equilibrium position. The friction coefficient is presented versus the misalignment angles and wear depths for different Sommerfeld numbers, thus creating friction functions dependent on misalignment and wear of the bearing. The variation in power loss of the rotor-bearing system is also investigated and presented as a function of wear depth and misalignment angles.

\section{Objectives Of This Research}

In this research, flexible shaft has been performed represented by using a circular shaft and notice the effect of the unbalance on the stresses produced during rotation. Several 
unbalances cases have been taken to explain it's effect on the produced stresses due to rotation. A MATLAB/ simulink software has been used to determine the reaction forces resulting from the rotational speed of the rotor, and the (ANSYS) program for the analysis of the stresses on shaft and bearings during rotation.

\section{Mechanical Model and Motion Differential Equation:}

The design of rotor-bearing system is shown in Fig. (1). The geometric centers of bearings, shaft and mass rotor are $\mathrm{O}_{1}, \mathrm{O}_{2}$ and $\mathrm{O}_{3}$ respectively. $\mathrm{M}$ and $\mathrm{m}_{\mathrm{j}}$ are the masses of rotor and journal bearings respectively. The dimensions and material properties are shown in Table(1).

Table (1): Dimensions and properties of the rotor. system.

\begin{tabular}{|l|c|c|c|c|}
\hline \multicolumn{1}{|c|}{ Description } & Unit $(\mathrm{m})$ & \multicolumn{3}{c|}{ Properties } \\
\cline { 2 - 2 } & & Young's Modulus (Pa) & Poisson ratio & Density $\left(\mathbf{k g} / \mathbf{m}^{3}\right)$ \\
\hline Shaft diameter & 0.024 & & & \\
\hline Length of the shaft & 0.75 & & & \\
\hline Rotor diameter & 0.24 & \multirow{2}{*}{$209 \times 10^{9}$} & \multirow{2}{*}{0.3} & \\
\hline Rotor thickness & 0.01 & & & \\
\hline Bearing diameter & 0.025 & & & \\
\hline Length of the bearing & 0.0125 & & & \\
\hline
\end{tabular}

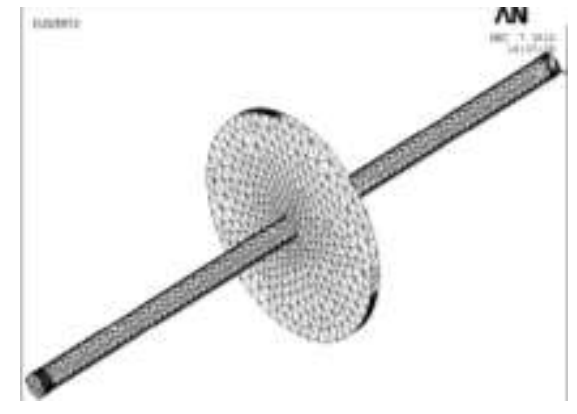

Fig.1 Model of rotor-bearing system supported by oil-film bearings.

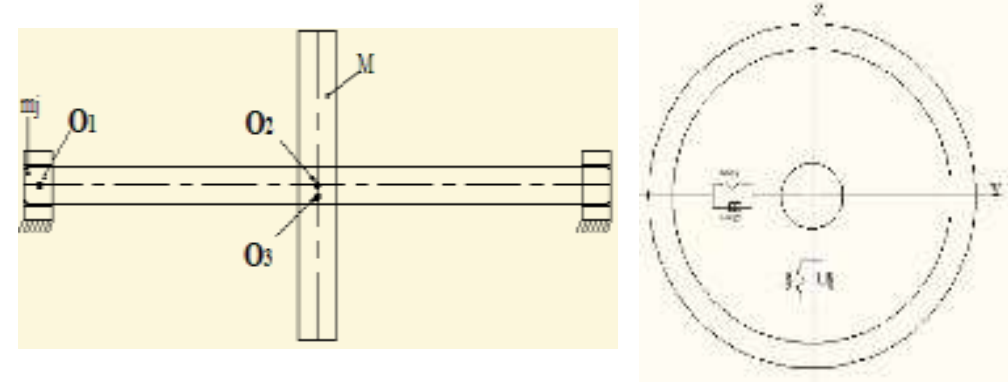

Fig.2 Journal bearing model.

The general non-linear equation of motion for the rotor response in the vertical and horizontal directions are as follows: [10]

$$
\begin{aligned}
& M \ddot{Y}_{2}+\left(K_{Y}\left(Y_{2}-Y_{1}\right)=M e \omega^{2} \cos w t\right. \\
& M \ddot{Z}_{2}+K z\left(Z_{2}-Z_{1}\right)=M e \omega^{2} \sin \omega t-M g \\
& m_{j} \ddot{Z}_{1}+K_{B Z Z} Z_{1}+C_{B Z Z} \dot{Z}_{1}=\frac{K_{Z}}{2}\left(Z_{2}-Z_{1}\right) \\
& m_{j} \ddot{Y}_{1}+K_{B Y Y} Y_{1}+C_{B Y Y} \dot{Y}_{1}=\frac{K_{Y}}{2}\left(Y_{2}-Y_{1}\right)
\end{aligned}
$$


Where $Y_{1}, \dot{Y}_{1}, \ddot{Y}_{1}$ and $Z_{1}, \dot{Z}_{1}, \ddot{Z}_{1} \quad$ are the displacement, velocity and acceleration of the bearings in $\mathrm{Y}$ and $\mathrm{Z}$ directions, while $Y_{2}, \dot{Y}_{2}, \ddot{Y}_{2}$ and $Z_{2}, \dot{Z}_{2}, \ddot{Z}_{2}$ are for the rotor in the same direction. $K_{Y}$ and $K_{Z}$ are the shaft stiffness in both directions. $K_{B Y Y}, K_{B Z Z}$ and $C_{B Y Y}, C_{B Z Z}$ are the stiffness and damping properties of the bearings, Fig. (2). Me $\omega^{2}$ and $M g$ represent unbalance and gravity forces respectively. e is the bearing eccentricity; and $\omega$ is the angular velocity of rotation.

\section{ANSYS}

A finite element analysis software ANSYS enables engineers to performing the important tasks. Build computer models or transfer computer Aided Drafting (CAD) models of structures, products, components, or systems. This involves the application and operating loads or other design performance conditions and studying the physical responses, such as stress levels, temperature distributions, or the impact of electromagnetic fields. Optimize a design early in the development process to reduce production costs [11]. Doing prototype testing in environments where it otherwise would be undesirable or impossible. The ANSYS program has a comprehensive graphical user interface (GUI) that gives users easy, interactive access to program function, commands, documentation, and reference material. The menu system helps users navigate through the ANSYS program. Users can input data using a mouse and keyboard or combination of both.

\section{Results and Discussion}

Numerical results are presented for this circular shaft of single rotor with three values of the eccentricity ( $\mathrm{e}=0.0001$ to 0.0003 ) to investigate the effect of the rotational speed $(\mathrm{N}=$ 750 to $2750 \mathrm{rpm}$ ) on stresses and deflections for the shaft and the bearings. The material properties that used were shown in Table (1), where; E, $\rho$ and $v$ represent modulus of elasticity, density and Poisson's ratio respectively. Stresses and deflections are obtained for all cases of eccentricity and rotational speed. Figures (3-6) show the Von-Mises stresses for different values of rotational speed and eccentricity. Many types of stresses and deflections in all directions for this shaft and bearings are obtained and discussed as follows:

Figure (7) shows the variation of $\left(\boldsymbol{\sigma}_{\mathbf{v o n}}\right)$ with $(\mathrm{N})$. At lower speeds even by increasing the eccentricity the values of $\left(\boldsymbol{\sigma}_{\mathbf{v o n}}\right)$ stay very close to one another in other wards they stay nearly unchanged then it starts to increase until the speed of $(1450 \mathrm{rpm})$ at which $\boldsymbol{\sigma}_{\mathrm{von}}$ are (103, 219 and 329) Mpa. for ( $(\mathrm{e}=0.0001,0.0002$ and $0.0003 \mathrm{~m})$ respectively. This is because of the resonance state which occurs in the system. The variation of $\left(\boldsymbol{\sigma}_{1}\right)$ with $(\mathrm{N})$ shown in Fig. (8). The stresses increase for higher speed from (34.3) to (71.2) Mpa. in the case of eccentricity ( $\mathrm{e}=0.0001)$, from $(34.4$ to $122 \mathrm{Mpa}$.) for $(\mathrm{e}=0.0002)$ and from $(34.5$ to 174 Mpa.) for $(\mathrm{e}=0.0003)$ with increase of $(\mathrm{N})$ from 750 to $2750 \mathrm{rpm}$ but it reaches maximum values which are (140, 282 and 441) Mpa. respectively for the speed of $1450 \mathrm{rpm}$ this is due to the same reason stated above.

From Fig. (9), it can be noticed that the variation of (Us) with (N). The values of (Us) stay very close to one another i.e nearly unchanged at low speeds and then increase at higher speeds (in the same path) from (121 to $318 \mu \mathrm{m}$ ) in the case of eccentricity (e=0.0001), from $(121$ to $571 \mu \mathrm{m})$ for $(\mathrm{e}=0.0002)$ and from $(121$ to $831 \mu \mathrm{m})$ for $(\mathrm{e}=0.0003)$ with increase of (N) from 750 to $2750 \mathrm{rpm}$ but it reaches maximum values which $\boldsymbol{\sigma}_{\mathrm{von}}$ are $(767,1582$ and 2401 
$\mu \mathrm{m})$ respectively at $(\mathrm{N}=1450 \mathrm{rpm})$. Figures $(10-13)$ show the Von-Mises stresses for different values of rotational speed and eccentricity on the bearings.

Figure (14) shows the variation of $\left(\boldsymbol{\sigma}_{\mathbf{v}}\right)$ with $(\mathrm{N})$. At lower speeds even by increasing the eccentricity the values of $\left(\boldsymbol{\sigma}_{\mathbf{v o n}}\right)$ stay very close i.e nearly unchanged then it starts to increase until the speed of $(1450 \mathrm{rpm})$ at which $\boldsymbol{\sigma}_{\mathrm{von}}$ are $(126.8,193$ and $270 \mathrm{Mpa}$.) for $(\mathrm{e}=0.0001,0.0002$ and $0.0003 \mathrm{~m})$ respectively. This is because of the resonance state which occurs in the system.

From Fig. (15) it can be noticed that the variation of (Us) with respect to (N) is negligible at low speeds and then increase at higher speeds (in the same path) from ( 0.2 to 5 $\mu \mathrm{m})$ in the case of eccentricity $(\mathrm{e}=0.0001)$ and from $(0.4$ to $7.5 \mu \mathrm{m})$ for $(\mathrm{e}=0.0002)$ and from $(0.7$ to $10 \mu \mathrm{m})$ for $(\mathrm{e}=0.0003)$ with increase of $(\mathrm{N})$ from 750 to $2750 \mathrm{rpm}$ but it reaches maximum values which $\boldsymbol{\sigma}_{\mathbf{v}}$ are $(11.1,24$ and $44 \mu \mathrm{m})$ respectively at $(\mathrm{N}=1450 \mathrm{rpm})$. Finally Table (2) can be optimized for all stresses and deflections for the rotor shaft and bearings.

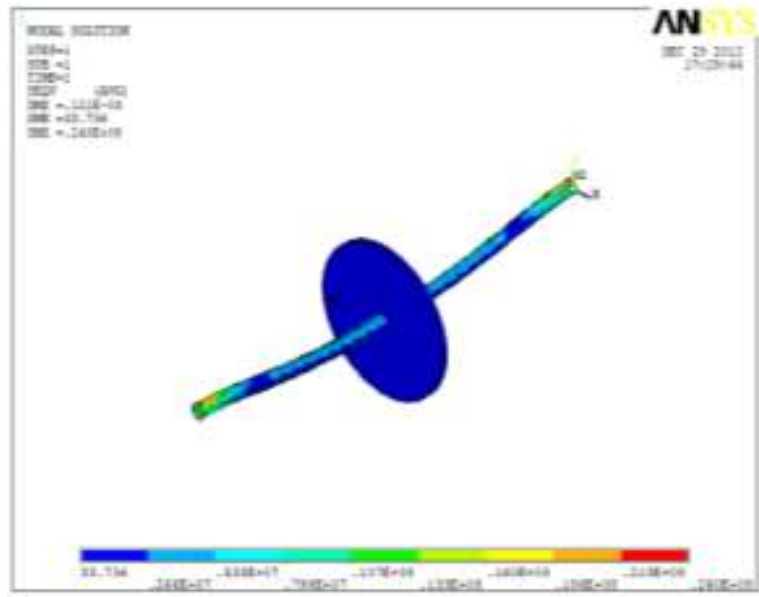

Fig.3 Contour of the stress distribution of $\left(\sigma_{\text {von }}\right)$ stress on the shaft at $(\mathrm{e}=1 \mathrm{e}-3 \&$

$$
\mathrm{N}=750 \mathrm{rpm}) \text {. }
$$

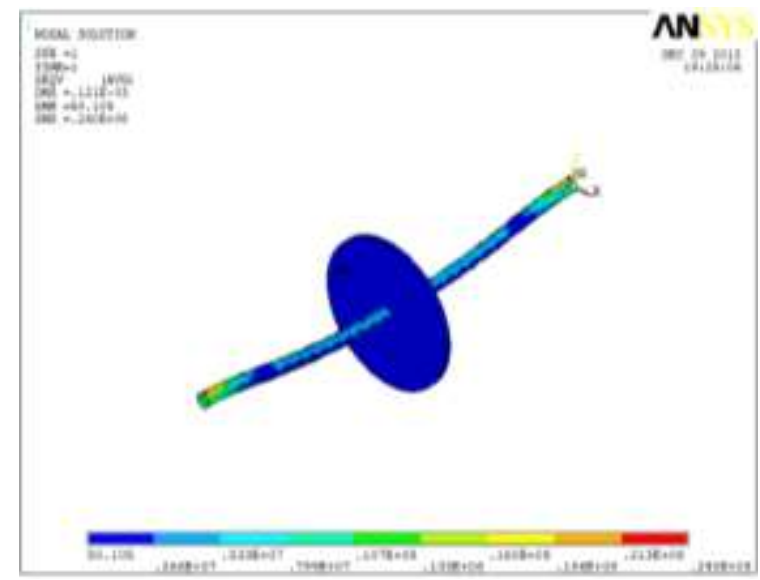

Fig.5 Contour of the stress distribution of $\left(\boldsymbol{\sigma}_{\mathrm{von}}\right) \quad$ stress on the shaft at $(\mathrm{e}=3 \mathrm{e}-3 \& \mathrm{~N}$ $=750 \mathrm{rpm})$.

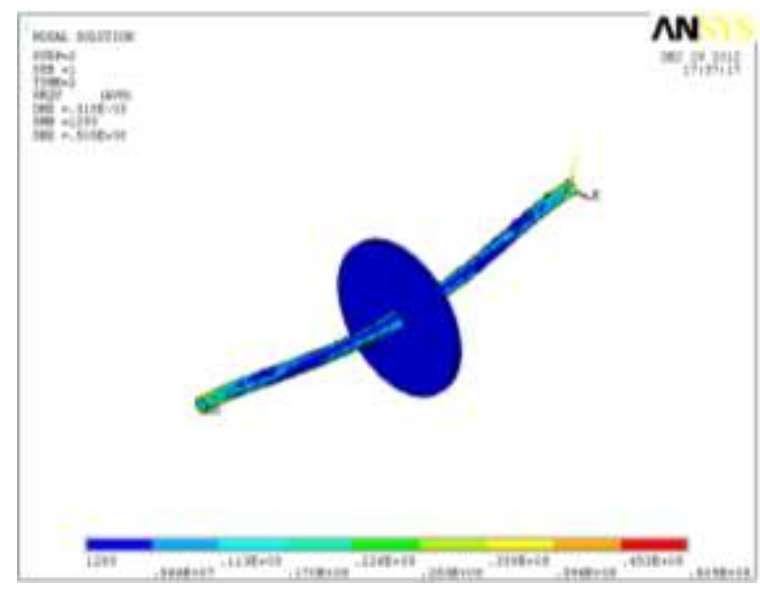

Fig.4 Contour of the stress distribution of $\left(\boldsymbol{\sigma}_{\text {von }}\right)$ stress on the shaft at $(\mathrm{e}=1 \mathrm{e}-3$ \& $\mathrm{N}=2750$ rpm).

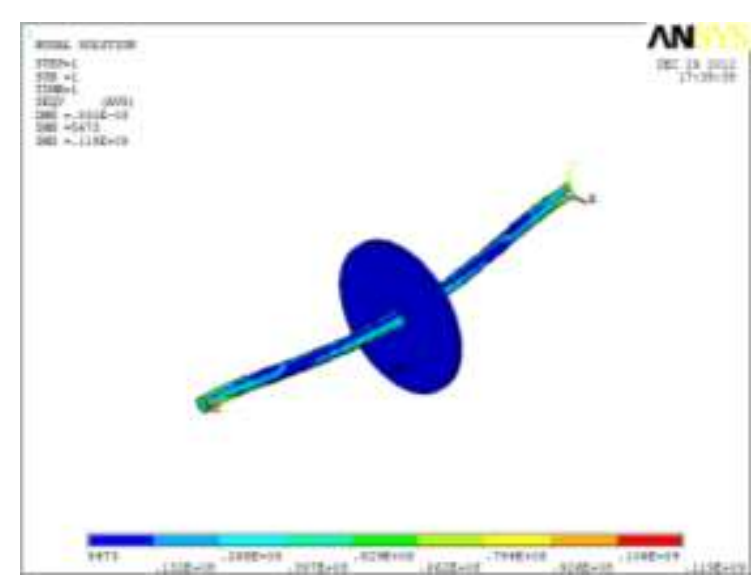

Fig.5 Contour of the stress distribution of $\left(\boldsymbol{\sigma}_{\text {von }}\right)$ stress on the shaft at $(\mathrm{e}=3 \mathrm{e}-3 \& \mathrm{~N}$ $=2750 \mathrm{rpm})$. 


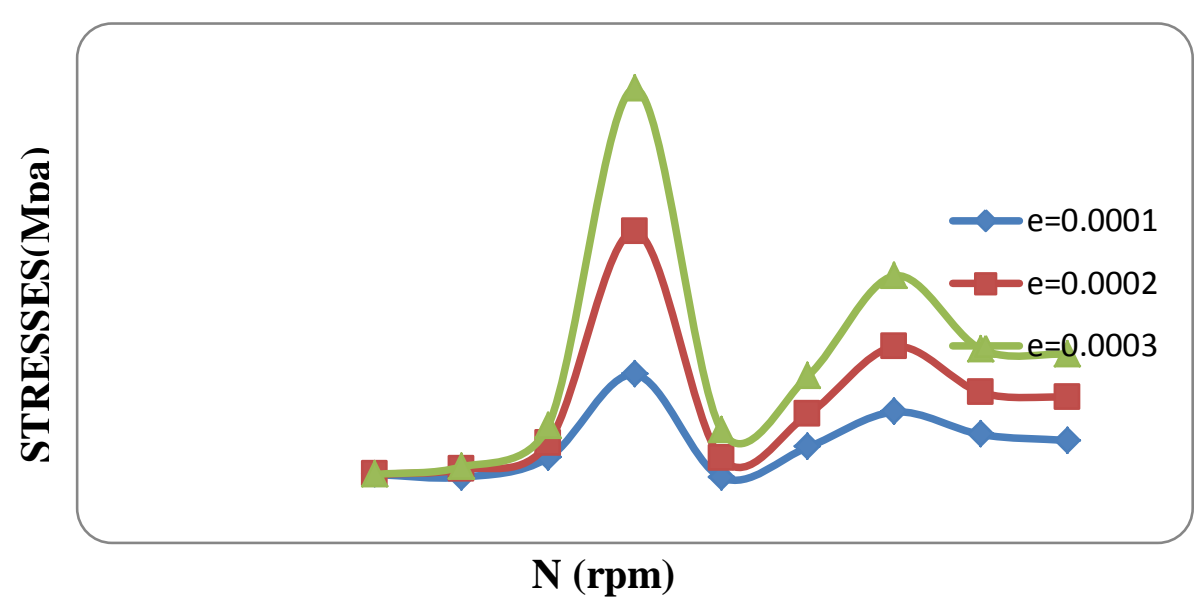

Fig. 7: Effect of Rotational Speed (rpm) on $\left(\boldsymbol{\sigma}_{\mathrm{von}}\right)$ in the shaft for three different values of eccentricity.

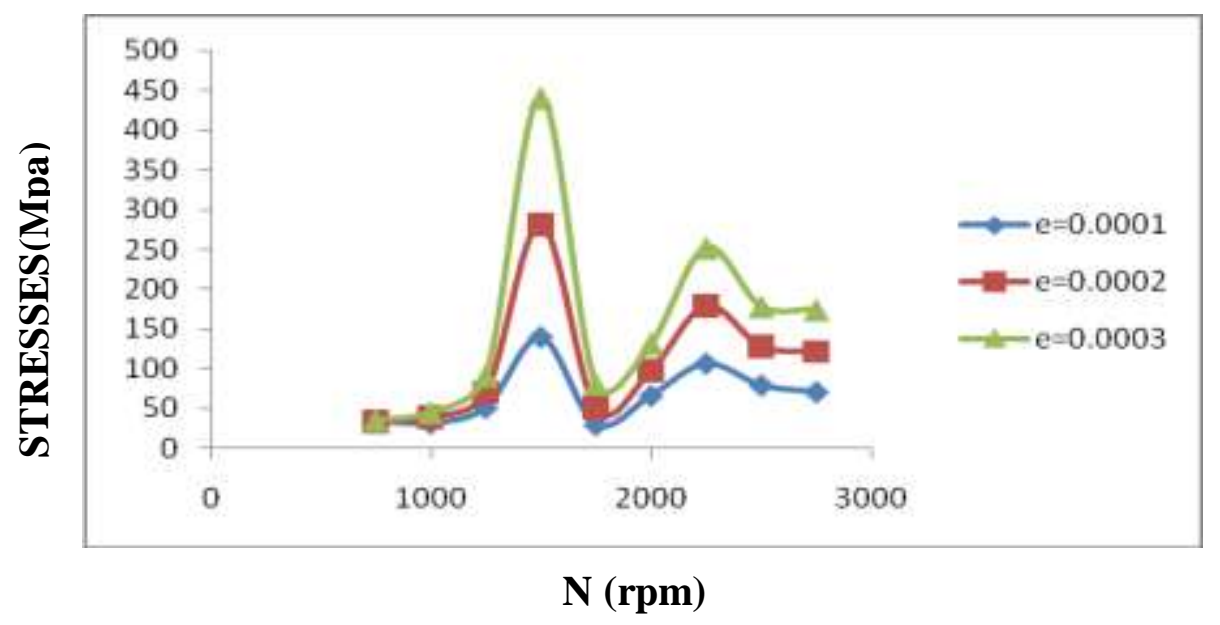

Fig. 8: Effect of Rotational Speed (rpm) on $\left(\boldsymbol{\sigma}_{\mathbf{1}}\right)$ in the rotor for three different values of eccentricitv.

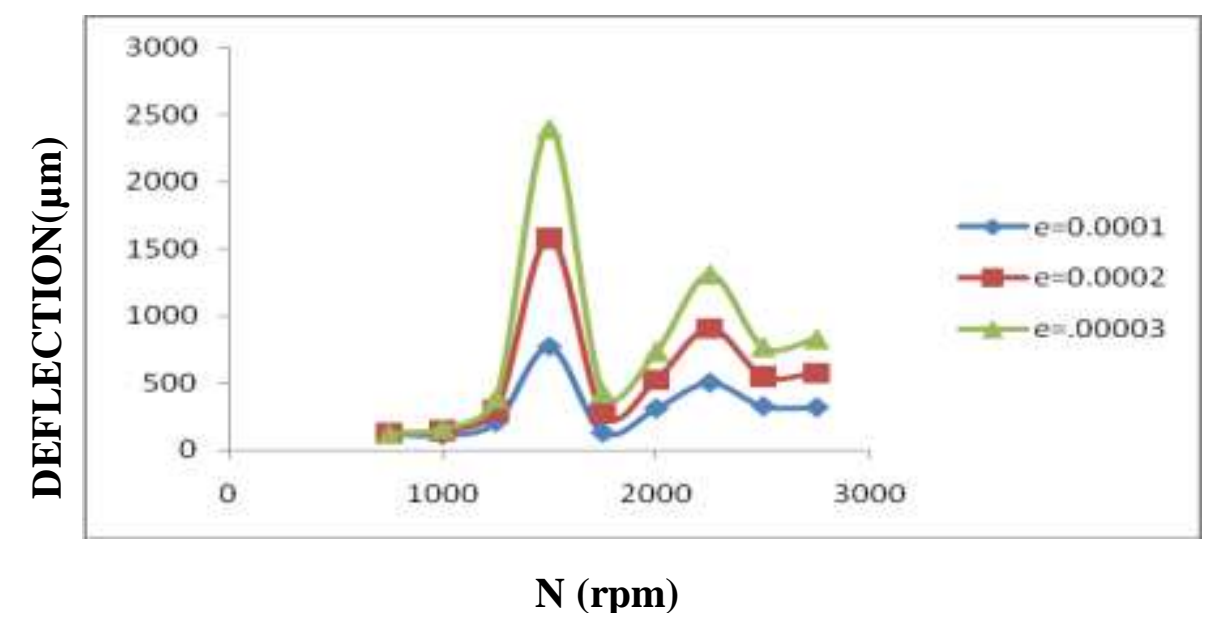

Fig. 9: Effect of Rotational Speed $(\mathrm{rpm})$ on $\left(\mathbf{U}_{\mathbf{S}}\right)$ in the shaft for three different values of eccentricity. 


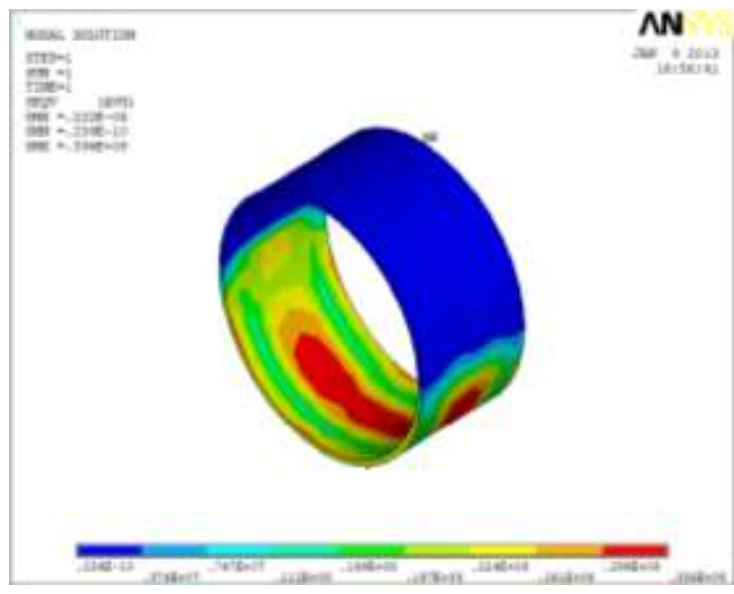

Fig. 12 Enlarge view of the stress distribution of $\left(\sigma_{\mathrm{von}}\right)$ stress on the bearing at $(\mathrm{e}=1 \mathrm{e}-3 \& \mathrm{~N}=750 \mathrm{rpm})$.

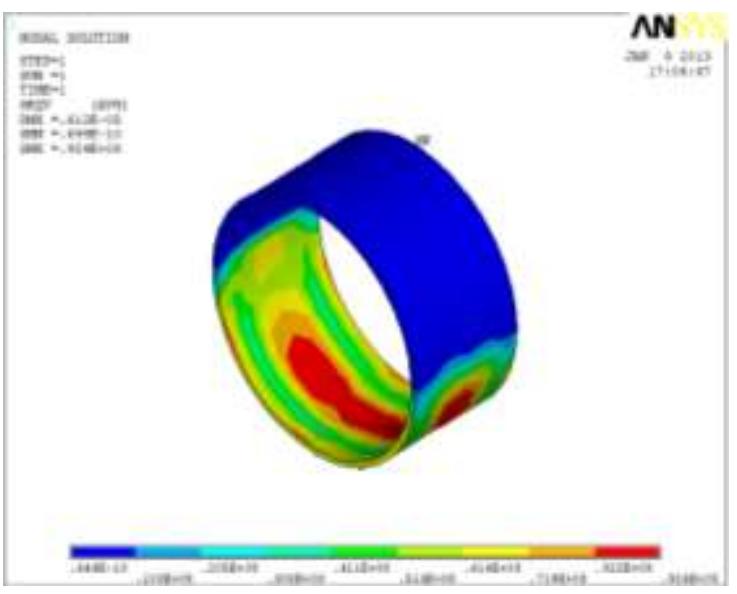

Fig. 12 Enlarge view of the stress distribution of $\left(\sigma_{\mathrm{von}}\right)$ stress on the bearing at $(\mathrm{e}=1 \mathrm{e}-3 \& \mathrm{~N}=2750 \mathrm{rpm})$.

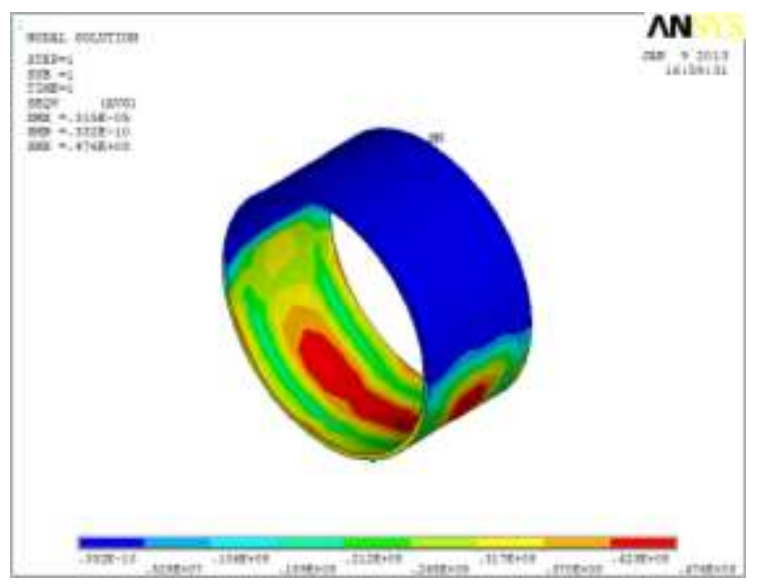

Fig. 12 Enlarge view of the stress distribution of $\left(\sigma_{\mathrm{von}}\right)$ stress on the bearing at $(\mathrm{e}=3 \mathrm{e}-3 \& \mathrm{~N}=750 \mathrm{rpm})$.

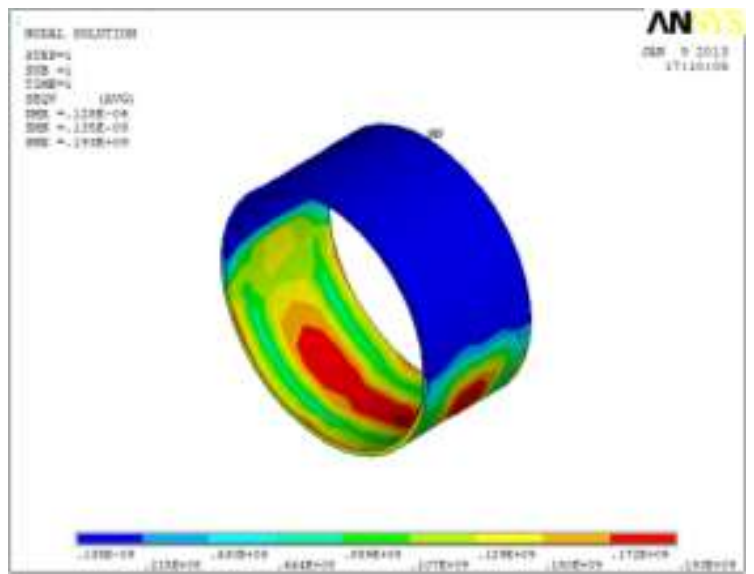

Fig. 12 Enlarge view of the stress distribution of $\left(\sigma_{\mathrm{von}}\right)$ stress on the bearing at $(\mathrm{e}=3 \mathrm{e}-3 \& \mathrm{~N}=2750 \mathrm{rpm})$.

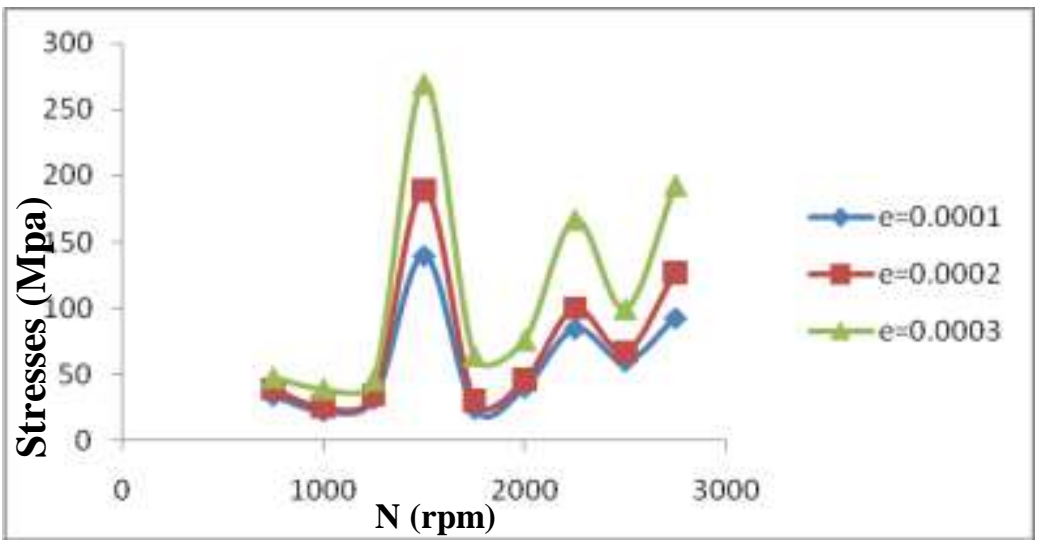

Fig. 14:Effect of Rotational Speed (rpm) on $\left(\boldsymbol{\sigma}_{\mathbf{v o n}}\right)$ in the bearing for three different values of eccentricity. 


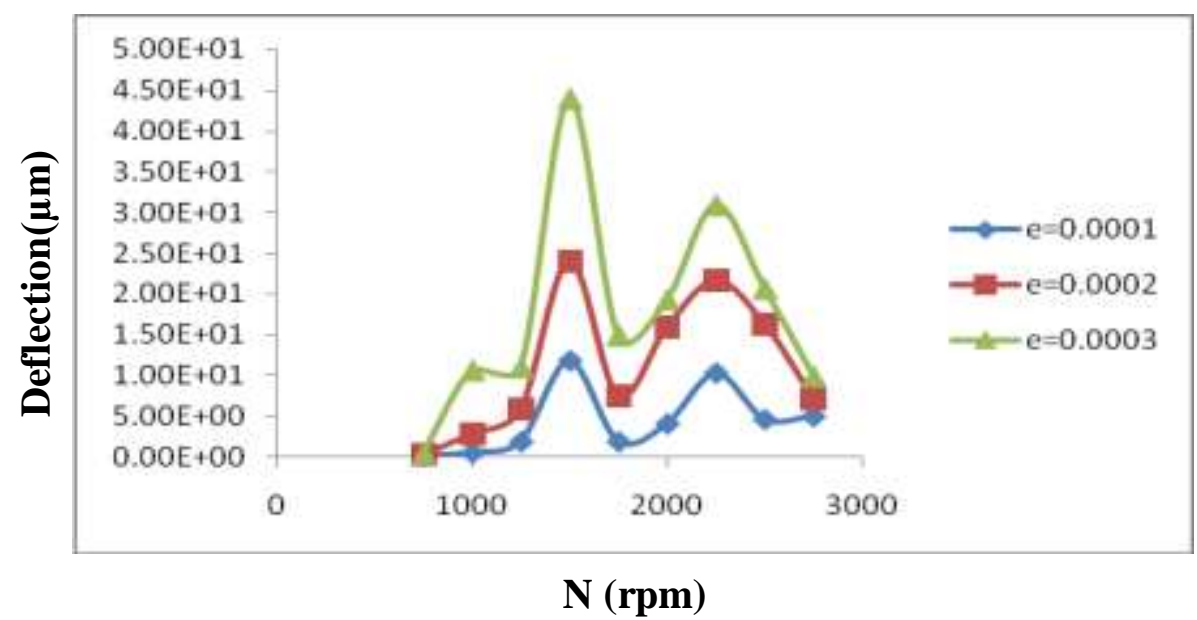

Fig. 15 Effect of Rotational Speed (rpm) on $\left(\mathbf{U}_{\mathbf{S}}\right)$ in the bearing for three different values of eccentricity.

Table (2): Results of all cases of the values of eccentricity and rotational speed

\begin{tabular}{|c|c|c|c|c|c|c|}
\hline \multirow{3}{*}{$\begin{array}{l}\text { Stresses \& } \\
\text { Deflections }\end{array}$} & \multicolumn{6}{|c|}{ Shaft } \\
\hline & \multicolumn{2}{|c|}{$\mathrm{e}=\mathbf{0 . 0 0 0 1}$} & \multicolumn{2}{|c|}{$\mathrm{e}=\mathbf{0 . 0 0 0 2}$} & \multicolumn{2}{|c|}{$\mathrm{e}=\mathbf{0 . 0 0 0 3}$} \\
\hline & 750rpm & 2750rpm & 750rpm & 2750rpm & 750rpm & 2750rpm \\
\hline$\sigma_{1}($ Mpa) & 34.3 & 71.2 & 33.9 & 122 & 34.5 & 174 \\
\hline$\sigma_{\text {von }}($ Мpa $)$ & 24 & 50.9 & 24 & 85 & 24 & 119 \\
\hline $\mathrm{U}_{\mathrm{S}}(\boldsymbol{\mu m})$ & 121 & 318 & 120 & 571 & 121 & 831 \\
\hline
\end{tabular}

\begin{tabular}{|c|c|c|c|c|c|c|}
\hline \multirow{3}{*}{$\begin{array}{l}\text { Stresses \& } \\
\text { Deflections }\end{array}$} & \multicolumn{6}{|c|}{ Bearings } \\
\hline & \multicolumn{2}{|c|}{$\mathrm{e}=0.0001$} & \multicolumn{2}{|c|}{$\mathrm{e}=0.0002$} & \multicolumn{2}{|c|}{$\mathrm{e}=\mathbf{0 . 0 0 0 3}$} \\
\hline & 750rpm & 2750rpm & 750rpm & 2750rpm & 750rpm & 2750rpm \\
\hline$\sigma_{1}$ (Mpa) & - & - & - & - & - & - \\
\hline$\sigma_{\text {von }}($ Mpa $)$ & 33.6 & 33.6 & 33.6 & 33.6 & 33.6 & 33.6 \\
\hline $\mathrm{U}_{\mathrm{S}}(\boldsymbol{\mu} \mathrm{m})$ & 0.167 & 0.167 & 0.167 & 0.167 & 0.167 & 0.167 \\
\hline
\end{tabular}

\section{Conclusions}

A finite elements simulation of rotor bearing system is presented in this work. The system includes the effects of rotary inertia and eccentricity. The stresses and deflections are increased with the increasing of eccentricity and rotational velocity and it can be noticed that there is a jump in the curves at $(\mathrm{N}=1450 \mathrm{rpm})$, which means that the system frequency reaches to its natural frequency (i.e. vicinity of resonance phenomena). It can be also noticed that:

1. The maximum deflection is take place at the midpoint of the shaft because of increasing weight in this place and this maximum deflection leads to occur a maximum stress.

2. For the case of bearings, the stresses and deflections are concentrating at the bottom half of the bearings due to focusing of forces on this area.

3. The effect of rotational velocity is the dominant factor with respect to the other factor (i.e. eccentricity) which can be considered a minor factor and has a secondary effect. 
4. Finally eccentricity has another effect on the values of stresses and deflections at $(\mathrm{N}=2250 \mathrm{rpm})$ and this effect was increased with the increasing of eccentricity and gives another reason to failure in addition of resonance

\section{References}

1. Chen, S. Y. et al, "Dynamic analysis of a rotary hollow shaft with hot-fit part using contact elements with friction". Transactions of the Canadian society for mechanical engineering, Vol. 35, No. 3, 2011.

2. Elmadany, M. M. et al, "On the dynamic analysis of rotor-bearing systems using finite elements". Mechanical Engineering Department, King Saud University, Riyadh, 1998.

3. Khonsari M.M. and Kim It. J. On thermally induced seizure in journal bearings. ASME J. of Tribology, 1989, 111, 661-7.

4. Hariharan, V. et al, "Vibration analysis of misaligned shaft-ball bearing system", Indian journal of science and technology, Vol. 2, No. 9, 2009.

5. Hannah, J. and Stephens, R. C. Mechanics of machines, 1997 (Edward Arnold, London).

6. Thomson, W. T. Theory of vibration with applications, 1972 (Prentice-Hall, New Jersey).

7. Al-khazali, H. A. et al, "Accurate identification of performance for rotor-bearing systems using the modified modelling under gyroscopic effect", International journal of modern engineering research, Vol. 1, Issue 2, pp-527-537.2009.

8. Pasha, H. G., "Dynamic of rotor-bearing systems using finite elements", Dynamics of rotor-bearings.

9. Nikolakopoulos PG, Papadopoulos CA. A study of friction in worn misaligned journal bearings under severe hydrodynamic lubrication. Tribol Int 2008;41:461-72. doi:10.1016/j.triboint.2007.

10. Imam, I. " Development of an on-line rotor crack detection and monitoring system", Journal of vibration, acoustics, stress and reliability in design ,Vol. 111/241, 1989.

11. Help of The ANSYS Program V12.0. (2010). 


\section{Appendix A}

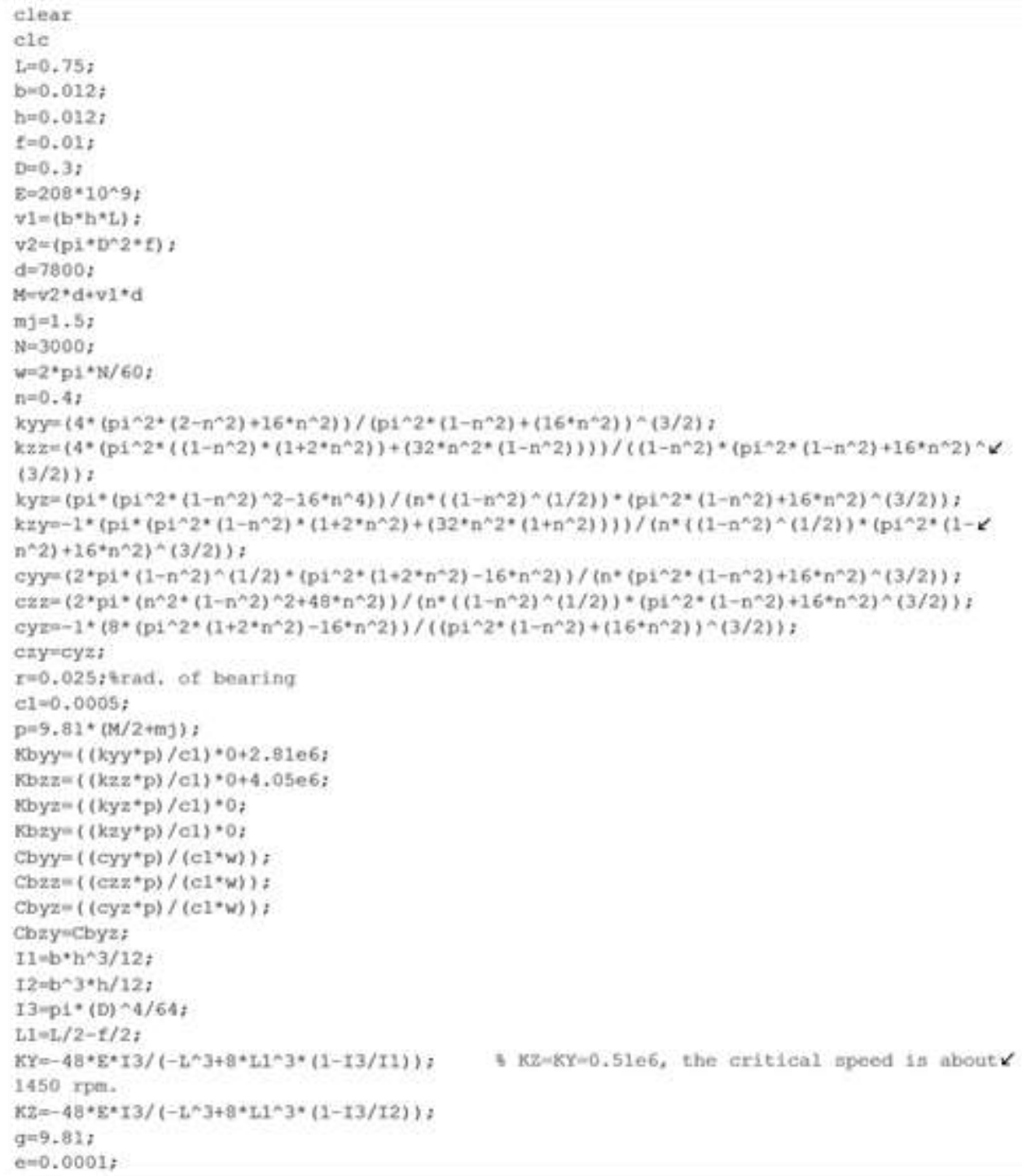

